\title{
Optimization of the Operation of Green Buildings applying the Facility Management
}

\author{
Viera Somorová \\ Slovak University of Technology \\ Faculty of Civil Engineering, Department of Building Technology \\ viera.somorova@stuba.sk
}

\begin{abstract}
Nowadays, in the field of civil engineering there exists an upward trend towards environmental sustainability. It relates mainly to the achievement of energy efficiency and also to the emission reduction throughout the whole life cycle of the building, i.e. in the course of its implementation, use and liquidation. These requirements are fulfilled, to a large extent, by green buildings.

The characteristic feature of green buildings are primarily highly-sophisticated technical and technological equipments which are installed therein. The sophisticated systems of technological equipments need also the sophisticated management. From this point of view the facility management has all prerequisites to meet this requirement.

The paper is aimed to define the facility management as an effective method which enables the optimization of the management of supporting activities by creating conditions for the optimum operation of green buildings viewed from the aspect of the environmental conditions.
\end{abstract}

Key words: energy effectiveness, facility management, KPs in green buildings, optimum operation, optimum working environment

\section{Introduction}

In general, the word optimization means the creation of the most suitable conditions that give the greatest advantages (for example: in the case of the plan, programme, process, etc.). In our case, the optimization of the operation of a green house represents the most suitable solution of its functioning with the aim to achieve to create optimal operation.

Precondition for optimal operation in relation to sustainability of green building is observance of projected parameters, which are basically projected parameters of sustainability in the operation phase. The problem of the green building consists in the fact that during the operation not all green buildings achieve the projected parameters of sustainability neither in the case of the excellent project nor in the situation of the perfect realization. 
One of the reasons of the non-observance of project parameters of sustainability is the management approach to the operation of green buildings lacking any system. The research is oriented so to develop a model of the optimum operation of green building by applying the facility management; the final aim is to come to the optimum operation from the viewpoint of the energetic effectiveness as a determinable and preferential project parameter of the sustainability of green buildings.

\section{Green buildings and Facility management}

A green building can be defined as an ecologically optimum construction exhibiting the minimum influence on the environment, starting from the phase of its implementation up to its introduction into the operation, use and liquidation. Green buildings are proposed and realized with the aim of sustainability to reduce an overall influence of the built-up environment on human health and environment by:

- an efficient utilization of the energies, water and other resources,

- a decrease of the pollution and waste volume.

For the efficient utilization of energies, water and other resources are ensured, above all, highly sophisticated technological equipments are installed in the green building. During the operation of green buildings highly-sophisticated technological equipments must fulfil the inevitable functions of ensuring their sustainability [1].

An assumption of the fulfilment of necessary functions is ensuring of their trouble-free course dependent not only on a high level of the information and communication technologies but also on their well-functioning technical administration.

One of the ways of ensuring the quality of the well-functioning technical administration of highly sophisticated technological equipments is the application of "the highly-sophisticated methods" of managing supporting activities, i.e. the facility management. According to the European standard EN 15221-1 Facility management - the technical administration is part of the technical infrastructure. Within the scope of the activity performed by the technical administration and in accordance with the standard the client's requirement for the technical equipment of the building (technical infrastructure) are satisfied by services providing an agreeable environment, light and shade, electric current, water and gas. Considering the system aspect, the facility management is the most convenient solution of the technical administration justified by the most efficient utilization of the synergy among individual technical-administration services.

The International Facility Management Association (IFMA) defined the role of the facility management in green buildings and devised a concept of the facility management in green buildings concurrently with the main conception of the sustainable development. The traditional spheres of 3P, which are characteristic for conformal buildings, give also environmental, economical and social sustainable benefits (Scheme 1). 
conformal buildings

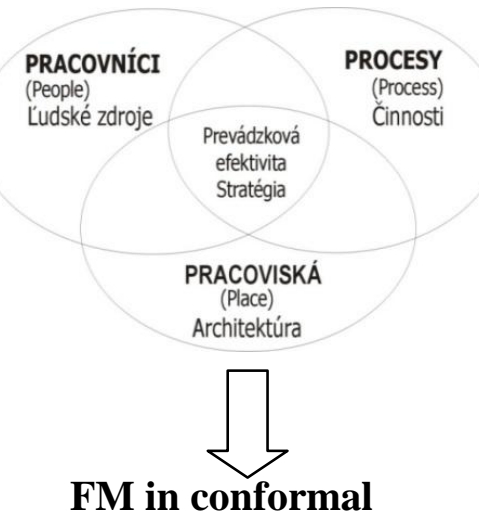

green buildings $=$ conformal buildings

+ benefits of sustainability: environmental

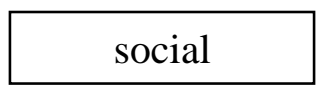

economical

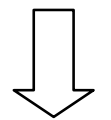

FM in green

\section{buildings}

Scheme 1: Facility management in green buildings

Benefits which can be received by the well-functioning administration being a part of the facility management are mainly the following:

Environmental benefits:

- the energy efficiency of buildings

- water protection, water saving

Economical benefits:

- a decrease of operating costs due to the reduction of energy consumption

- natural lighting, the correctly adjusted ventilation and room temperature

- better protection of the health of employees

Social benefits:

- an increase of the employees' comfort and health associated with the quality of the indoor environment (air circulation, lighting, temperature).

The aim of the facility management is to reinforce all processes by which people at their workplaces - in a comfortable and supportive performance environment - make optimal performance, i.e. help to ensure an optimal working environment for users of buildings [2]. This is just the aim of green buildings which should enable the comfortable and safe environment for users, their protection at the time of their stay in these buildings, and their comfort and working environment which would offer them to attain the maximum working performances.

An important factor in the creation of the optimum working environment is the optimum operation of green buildings with a failure free operation of the technological energysupplying equipments in buildings (heating, electrical energy, air-conditioning, etc.). 


\section{Optimization model of the operation in green buildings}

The optimum operation which is an objective of the optimization can be achieved by adhering to the projected parameters of sustainability (PPS) which result from the project documentation. An effective form of the technical administration which will enable the fulfilment and observance of PPS can be achieved by applying the facility management [3].

The essential phenomenon is the quality of processes proceeding in the technical administration. A useful tool for monitoring the quality of the performed processes is the permanent checking of their quality on using a form of the PDCA (plan-do-check-adjust) management quality.

The optimization system of the operation is represented by the illustrated model (Scheme 2):

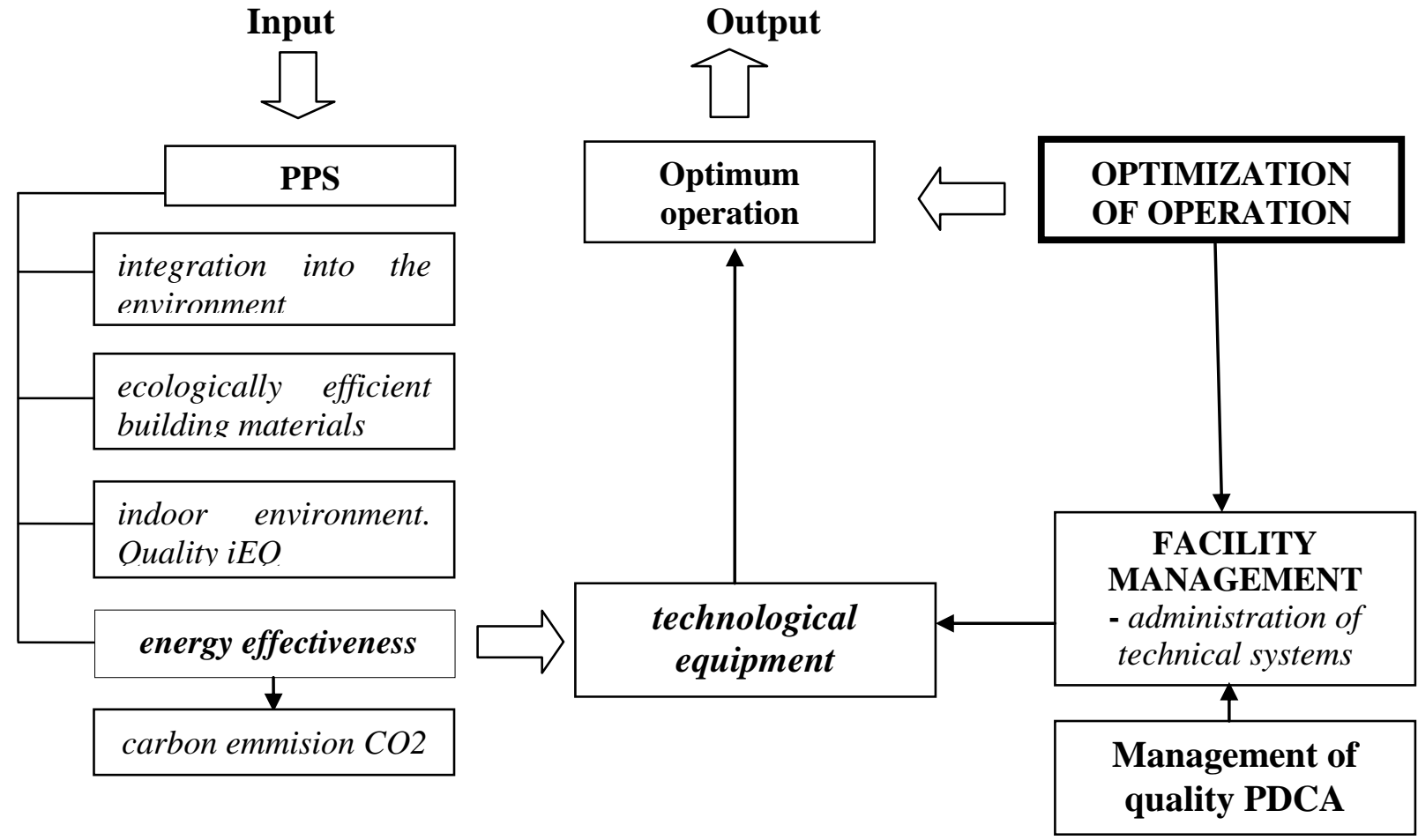

Scheme 2: Optimization model of the operation in green buildings

The course of steps in the optimization of the operation of green buildings:

1. The definition of input data - input data are projected parameters of sustainability (PPS) of green building, that are given by a project documentation. Based on the fundamental principles characterizing green buildings the parameters of sustainability are defined as follows:

- integration into the environment in which the building is situated,

- ecologically efficient building materials,

- the indoor environmental quality,

- energy effectiveness . 
2. The definition of the key projected parameter of sustainability in relation to the operation The indoor environmental quality (iEQ) is given primarily by the quality of indoor atmosphere. The indoor environmental quality of green buildings is ensured by highly sophisticated technological equipments which are installed therein. They ensure primarily the projected energy effectiveness of heating, cooling, water heating, illumination, etc. as well as the desirable quality of the indoor working environment (air exchange) and the operative regulation of the indoor atmosphere. The correctly proposed HVAC (Heating, Ventilation and Air-Conditioning) system permits the sufficient ventilation and air filtration. The next important factor is the thermal and illumination quality [4].

It can be stated that the determinable design parameter of sustainability in relation to the operation is the energetic effectiveness of highly-sophisticated technological equipments. If the technical parameters of equipments determined by producers are maintained, then the projected parameter of sustainability (PPS) - energy effectiveness -will also be maintained.

Notice: By lowering the energy consumption the carbon monoxide emissions (CO2) released into the environment are subsequently reduced

3. The application of the facility management in the administration of technical systems - An important part of the technical administration is provide a failure free operation of the technological equipment for compliance with the PPS.

The application of the facility management in the administration of technical systems of green buildings calls for the regular maintenance and obligatory inspections which serve as a basis for elaboration of the preventive maintenance plan. In the technical administration of green buildings the preventive maintenance of equipments must be kept by a facility manager in the same way as in standard buildings and the revisions of equipments must be carried out according to respective instructions and regulations.

The role of the maintenance is to ensure the lower rate of failures, longer lifetime and the appropriate functionality of technical and technological equipments. The management of the maintenance must be planned and performed according to the schedule of regular preventive maintenance works at regular time intervals. The technical administration must also perform:

- detection of failures,

- ensuring the early assistance of maintenance workers in the case of incurred failures to avoid the subsequent damages,

- monitoring of technical and technological equipments,

- receipt of requirements for services, for example, through the help desk or service line.

In order to analyze and assess the maintenance performance of equipments a record must always be done after finishing the works. In this connection, the number of workers necessary for the execution of works, the required material and spare parts are also assessed. The information is a background for the next planning of the technological regular-maintenance procedure which can include also the technological procedure of repairs, the distribution according to individual working steps, etc. [5] 
As an example of the process sheet and KPIs determination it is possible to indicate the process sheet for the "Maintenance of heating equipments". In the process sheet the organization will specify:

- subject of the process. The maintenance process of heating equipments incorporates the maintenance of pumps, heaters, etc.,

- demanded professional competence for the execution of works,

- respective standards and regulations including internal standards and regulations,

- required technical and technological equipments for the maintenance performance of heating equipments,

- determination of the respective maintenance frequency and the process duration in the case of the output-oriented service level,

- detailed process description of individual equipments as, for example, in the case of heaters incorporating:

- control of tightness,

- control of corrosion,

- control of the functionality of air-release valves,

- control of the fastening of hangers,

- performance and quality measurement: measuring units for the performance measurement and key performance indicators - KPI. They serve for the continual control of heating equipments.

The example for establishing the KPIs scale, which is based on the number of failure states, is following:

- 3 the heating equipment is permanently without any failure. The assessment expresses the state claimed by the organization (client) within the service level agreement (SLA),

- 2 in the winter period the heating equipment is exhibited to a single failure which is eliminated up to 2 hours. The organization (client) can suggest the penalization, for example, by reducing the invoiced sum by $5 \%$,

- 1 in the winter period the heating equipment is exhibited to a failure 3 times - it is eliminated up to 2 hours. The organization (client) can suggest the penalization for a provider, for example, in the form of reducing the invoiced sum by $10 \%$,

- 0 in the winter period there exists a permanent shut-down. The impacts on the organization (client) justify it (him) to arrange the improvement by an instant negotiation (or by a change in the maintenance system, or in the notice, i.e. by a cancellation of the agreement with a provider, etc.).

Besides the above-indicated KPIs it is possible to create and monitor the KPIs associated with the projected parameters of heating equipments and to ascertain, in which way are the requirements for the energy efficiency of heating equipments fulfilled [6] .

4. The definition of the quality of the technical administration - Management of quality (PDCA) [7]

An important part of the technical administration is provide a failure free operation of the technological equipment for compliance with the PPS. Management of quality (PDCA) on technical administration in facility managementmeets is shown in the next scheme $3(\mathrm{QM}=$ Quality measurement): 


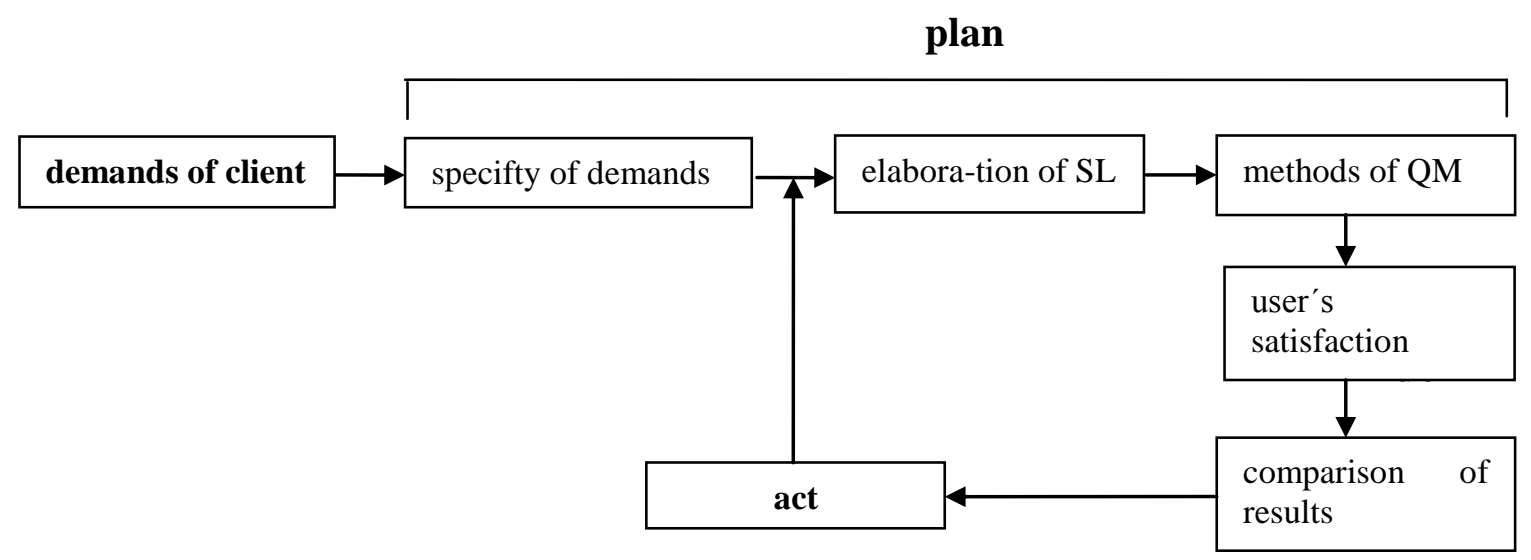

Scheme 3: Management of quality

The management of quality is aimed to ensure the maintenance of technological equipments in such a quality to fulfil the requirements of the organization (client) for their continual failure-free operation, to ensure the optimization of the maintenance process and the continual improvement. The process of the maintenance quality of technological equipments includes these requirements:

- the organization (client) defines its requirements for the maintenance of technological equipments; the requirements include its description and specification inclusive of the maintenance performance and quality checking; they create the basis for making an agreement about the level of services (Service Level Agreement - SLA),

- the specification of requirements which can be worked out according to STN EN 15221-2 inclusive of the maintenance performance and the views of quality,

- the elaboration of the service level (SL); the organization (client) will stipulate a level of the maintenance conditions by a precise description of the maintenance input (inputbased) either at the entrance or at the output (output-based) where it defines the result which is to be achieved by the maintenance of heating equipments; it will determine the KPI (Key Performance Indicator) quality indicators,

(Notice: The result of SL is Process sheet and KPI for maintenance of technological equipment.)

- the definition of methods of measuring the quality,

- realization of the maintenance of technological equipments,

- the results of measurements are determined by an auditor or by a client's satisfaction,

- the comparison of results with requirements for the quality of rendered services (SL),

- the analysis of potential deviations from the demanded maintenance level; for deviations beyond the limits set in SL draws up a new SL for demanded operation - maintenance. The result is - the optimization of the maintenance of technological equipments [8].

The specification of requirements, elaboration of the service level (SL) and the definition of methods for measuring the quality are part of the $\mathbf{P}$ phase (plan) followed by the performance of services $\mathbf{D}$ (do). The phase of checking $\mathbf{C}$ (check) includes audit and the comparison with requirements for the quality of provided services. The analysis is a part of the phase $\mathbf{A}$ (act). On the basis of the results gained by the analysis the optimization of rendered services is determined and the whole check cycle is repeated. 


\section{Conclusion}

In this period of time, when there exists a trend of decreasing the energy consumption not only from the aspect of costs but primarily from the viewpoint of the accessibility of their sources, green buildings considered the energetically effective structures with a minimum negative influence on the environment are an urgent problem of the present time.

Energy efficient, and thus the economic effectiveness of green buildings is defined already at their designing realized on a basis of the proposal for highly sophisticated technological equipments with projected parameters serving as the projected parameters of sustainability in green buildings. The observance of given projected parameters of the equipments is an assumption of creating the optimum operation ensuring the optimum working environment for users of the green house.

A tool for achieving the optimum operation is a choice of the most convenient technical administration of the highly sophisticated technological equipments. The application of the facility management in the technical administration and co-operation with quality management will permit to develop the optimum operation and achieve the multiplication effect of the energetic effectiveness of sustainable buildings of a given projected parameters of sustainability.

\section{Acknowledgements}

The paper has been elaborated within the VEGA grant 1/0184/122.

\section{References}

[1] Yudelso, J. (2009). Green building Trends: Europe. , USA, Island Press, Washington.

[2] Riley, M., Cotgrave, A. (2012). Total Sustainability in the Built Environment, UK, Palgrave Macmillan.

[3] Somorová, V. (2011). Zelené budovy a facility management, TZB Haustechnik. Vol.19, No.3, pp-16-17.

[4] Smith, D.L. (2011). Environmental Issues for Architecture, USA, Wiley.

[5] Vyskočil,V., Štrup,O. (2003). Podpůrné procesy a snižování režijních nákladu Facility management. Praha, PROFESSIONAL PUBLISHING.

[6] Rimbalová, J., Vilčeková, S. (2013). The Proposal of Key Performance Indicators in Facility Management and Determination the Weights of Significance, Selected Scientific Papers - Journal of Civil Engineering. Roč. 8, č. 2 (2013), s. 73-84. - ISSN $1338-7278$

[7] STN EN 15221-3 Quality in Facility management, (2009). Bratislava, SÚTN.

[8] Singovszki, M., Vranayová, Z. (2013). Evaluation of facility management by multivariate statistics - factor analysis, Selected Scientific Papers : Journal of Civil Engineering. Roč. 8, č. 1 (2013), s. 79 - 86. - ISSN 1338-7278. 